\title{
Guide for authors of the Netherlands Journal of Geosciences / Geologie en Mijnbouw
}

Revised 03-April-2002

1 Manuscripts should be within the scope of the journal, i.e. refer to the North Sea region and geologically relevant adjacent areas. The subject should be of interest for a worldwide readership.

2 Manuscripts should preferably not take more than 8 printed pages, including the illustrations. A printed page with text only comprises - from volume 79 (2000) on - some 750-775 words, which should allow a fairly accurate estimate of the length of the text in printed form. For manuscripts of more than 12 printed pages, 50 Euro per additional page will be charged (p 13 etc.). Colour pages cost 500 Euro per page.

3 Manuscripts should be submitted electronically and be accompanied by 3 printed copies (with double spacing and wide margins), the carrier should be clearly labelled and dated. They should be sent to the Editorial Office. Details for the electronic submission are provided underneath.

4 In the case of a multi-author manuscript, it should be clearly stated who is the corresponding author. The corresponding author will receive the proofs, a reprint-order form, and the form for copyright transfer. The corresponding author should, if possible, provide an e-mail address with other address data; co-authors are strongly advised to do so, too.

5 Submission of a manuscript is understood to imply that it has not been, and is not being, considered for publication elsewhere. Manuscripts that have been published previously, partly or in full, in a language other than English, French, German or Spanish may be considered for publication; the original publication should be mentioned explicitly in the accompanying letter.

6 Manuscripts must be written in English. Authors whose native language is not English, are urged to have their text corrected by a colleague who has English as his mother-tongue. The use of a spelling checker as present in most word-processing software is strongly advised, the agreed spelling for NJG is English (UK). Manuscripts that would require much language correction, may be rejected. If accepted, their handling will not have the highest priority.

7 Authors should adhere to IUGS terminology. SI units should be used wherever possible; details on this system are to be obtained from OFFILIB, 48 Rue Gay-Lussac, F-75005 in Paris. Non-SI units may be used only where this is necessary for practical understanding.

8 Manuscripts should generally be organized in the following order: (1) title; (2) name(s) of the author(s); (3) the author(s) affiliation(s) and e-mail address(es); in the case of more than one author, please, indicate to whom the correspondence should be addressed; (4) abstract; (5) keywords (in alphabetical order); (6) introduction; (7) methods and materials; (8) results and analyses; (9) discussion and conclusions; (10) acknowledgements; (11) references (according to the format detailed below); (12) appendices (if any; their use should be restricted to a minimum); (13) tables; (14) figure and table captions; (15) figures.

The Editors reserve the right of returning a manuscript to the author for revision prior to the review procedure if it is not in the form given in this guide.

The title should be as concise as possible, but leave no doubt as to the contents. Area and age of studied material should - if appropriate - be mentioned. Abbreviations in the title should be avoided. Names etc. should contain all relevant diacritical symbols required.

The abstract should not be descriptive but rather be a concise summary stating the methods used, the main results and the conclusions; it must be understandable on its own and not refer to illustrations or references. It should not be longer than 500 words.

Keywords should preferable amount to 3-6. They should preferably be taken from the most recent American Geological Institute GeoRefThesaurus. A single keyword should not consist of more than three words, but preferably of one.

The running text should be subdivided into chapters and - if required - sections and subsections. The headings are, respectively, in bold (with a white line underneath), in italics (with a white line underneath), and in italics (without a white line underneath). Chapters, sections and subsections should not be numbered. Unduly long descriptions should be replaced by tables or figures, whenever possible. 
All references cited in the text are to be listed in the reference list (and vice versa). The manuscript should be carefully checked to ensure that the spellings of authors' names and publication years are exactly the same in the text as in the reference list. Do not type anything in bold or italics. Do not abbreviate journal titles. Refer in the text to the author's name (without initials) and year of publication: 'as suggested earlier (Smith, 1999)' or 'as suggested by Smith (1999) and Johnson \& Petersen (2000)'. If reference is made to publications written by more than two authors, the name of the first author should be used, followed by 'et al.'. This indication should, however, never be used in the list of references: all names of authors and all co-authors must be given in full in the list.

References in the text should be arranged chronologically. The reference list should be in the form as in Geologie en Mijnbouw / Netherlands fournal of Geosciences from volume 79 (2000) on. The list of references should be arranged alphabetically by authors' names, and chronologically per author. If an author's name in the list is also mentioned with co-authors, the following order should be used: (1) publications by the single author, arranged according to publication year; (2) publications of the same author with one co-author, arranged alphabetically per co-author and, if necessary, per co-author according to publication year; (3) publications of the author with more than one co-author, arranged chronologically (per year, if necessary, alphabetically).

The following system should be used for arranging references:

1 Journal papers: names and initials of all authors, year. Title of paper. Journal name (in full), volume number: first and last page numbers of the paper. Issue numbers should be provided between brackets after the volume number, but only if the issues of one volume do not show consecutive page numbering.

Example: Louwije, S., De Coninck, J. \& Verniers, J., 1999. Dinoflagellate cyst stratigraphy and depositional history of Miocene and Early Pliocene Formations in northern Belgium (southern North Sea Basin). Geologie en Mijnbouw 78: 31-46.

2 Books: names and initials of all authors, year. Title of the book. Publisher (location of publisher): page numbers.

Example: Brodzikowski, K. \& Van Loon, A.J., 1991. Glacigenic sediments. Elsevier Science Publishers (Amsterdam): $674 \mathrm{pp}$.

3 Edited volume papers: names and initials of all authors, year. Title of paper. In: Names and initials of the volume editors: title of the edited volume. Publisher (location of publisher): first and last page numbers of the paper.

Example: De Jong, J.D. \& Maarleveld, G.C., 1983. The glacial history of the Netherlands. In: Ehlers, J. (ed.): Glacial deposits in North-West Europe. Balkema (Rotterdam): 353-356.

In the case of publications in any language other than English, the original title is to be retained. Titles of publications in non-Latin alphabets should be transliterated, and a note such as '(in Russian)' or '(in Japanese, with English abstract)' should be added at the end of the reference.

All illustrations must be presented separate from the manuscript. The design, line widths, letter sizes and scale bars should allow reproduction at column width, $120 \mathrm{~mm}$ width, or page width in such a way that the 'information density' is high. All illustrations must be numbered consecutively and referred to in the text in the same order. Numbers of electronic files and printed figure numbers must be the same. Foldouts and colour figures are possible. The author should indicate this and state explicitly that the cost will be paid.

Drawings must be sharp and drawn at high density on bright white paper, on glossy paper or on drawing film. The same type of lettering should be used throughout. Authors are recommended to submit clearly legible copies when submitting a manuscript, and to keep the originals until the manuscript has been accepted by the Editors.

Photographs and micrographs, etc. must be sharp and exhibit good contrast. Original glossy prints (e.g., from negatives) are required. Reproductions of photographs cannot be accepted. The object being shown must fill the image. Bar scales on the photograph must be used rather than magnification factors in the caption.

Each illustration should be identified on the reverse side, on the lower front side by its number and the name of the principle author. Indicate the top of the illustration in cases where doubt may arise.

Colour figures or plates will be charged at 500 Euro per page. (i.e. Two colour figures on one page cost 500 Euro, on two separate pages this will be 1000 Euro).

Tables should not exceed the printed area of the page. If this appears impossible, reversing columns and rows will often make the impossible possible, but large tables should be avoided. Tables should be compiled on separate sheets and must be numbered according to their sequence in the text. Electronic files must have the same num- 
bering as printed versions. The text must include references to all tables. Column headings should be brief, but sufficiently explanatory. Units of measurement should be given in parentheses. See the tables in volume 79 of the journal for additional details on layout, etc.

Tables should not be prepared with an electronic table format, nor by using spaces, but rather by using tabs. Each table must have a brief and self-explanatory caption. Explanations that are necessary to the understanding of the table should be given as footnotes at the bottom of the table. A footnote should be indicated by a superscript number.

All formulae should be presented consistently and clearly with regard to the meaning of each symbol and its correct location. Formulae must be typed throughout. All unusual symbols must, if numerous, be collected in a separate list in an appendix, giving a clear explanation of each symbol. Please, try to keep the notation as simple as possible, and avoid ambiguities. Do not use special type fonts if there is no urgent need to do so. Different formulae should be clearly separated in the manuscript, at least by punctuation marks, if not by words. Avoid breaking formulae if breaking is not strictly necessary (i.e., if the equation is less than one typed line). Do not use complicated juxtapositions of symbols. Also, try to avoid complicated subscripts and superscripts; third-order indices especially present difficulties as to their size and position, fourth-order indices are not permitted.

Formulae and text should show a clear distinction between similar symbols, (e.g., between zero $(0)$ and the letter $\mathrm{O}$, between one ( 1 ) and the letter $\mathrm{I}$, and between multiplication $(\cdot)$ and the letter $\mathrm{x}$.

Footnotes should be used only if absolutely essential. In most cases it will be possible to incorporate them in the main text. If used, footnotes should be numbered consecutively throughout the manuscript, indicated by superscript Arabic numbers, and kept as short as possible.

One set of page proofs will be sent to the corresponding author to be checked for typesetting/editing. The author is not expected to make changes or corrections that constitute departures from the article that was accepted by the editor. Text changes may be charged to the author at cost price.

Fifty reprints of each article are supplied free of charge. Additional reprints can not be supplied.

Copyright: Upon acceptance of an article by the journal, the author(s) will be asked to transfer the copyright of the article to the Netherlands fournal of Geosciences Foundation. This transfer will ensure the widest possible dissemination of information. The author(s) will be allowed to re-use their material for other scientific work without explicit permission by the foundation.

The author is responsible for obtaining permission to use any copyrighted material. When quoting from someone else's work or when considering reproducing an illustration or table from a book or journal article, the author should ensure that he is not infringing copyright. Although in general an author may quote from other published works, he should obtain permission from the copyright holder if he wishes to use substantial excerpts or to reproduce tables, plates, or other illustrations. If the copyright holder is not the author of the quoted or reproduced material, it is recommended that the permission of the author in question is also sought. Note: material in unpublished letters and manuscripts is also protected and must not be published unless permission has been obtained.

\section{Electronic submission}

All texts, and preferably the figures as well, should be submitted in electronic form. In order to avoid unnecessary delay, we advise you to adhere to the following instructions.

Text and figures should be stored in separate files with clearly identifiable file names. The format of these files depends on the word processor used. We prefer Microsoft Word for Windows, Word Rich Text Format, Corel WordPerfect (up to 8.0), or ASCII; Page Maker may also be accepted. It is essential that the name and version of the word processing program, the type of computer on which the text was prepared and the format of the text files, are clearly indicated in the accompanying letter.

The contents of the disc should correspond exactly to the contents of the hardcopy manuscript. Discrepancies can lead to proofs of the wrong version being made. The word-processed text should be in single column format. Keep the layout of the text in line with the guidelines provided above; in particular, do not use the word processor's options to justify or to hyphenate the words. Please, refrain from using so-called styles, as these may induce severe mis- 
takes during conversion procedures; do not use (report) templates. Do not include figures in a word-processing document, always provide figures as separate files, do not submit figures in a word-processing format.

We will handle electronic figures prepared in CorelDraw, Illustrator, Freehand, (if saved in the original format of the program ${ }^{\star}, \mathrm{cdr},{ }^{\star}$.ai, ${ }^{\star} \ldots . .$. or as, .eps, files). Photoshop files and Corel Photopaint files should be delivered in their original formats $\left({ }^{\star}\right.$.psd) or in tiff (*.tif) format.

Figures should preferable be submitted on $650 \mathrm{Mb}$ CD-ROM or $100 \mathrm{Mb}$ ZIP disc. Both IBM PC format and Apple Macintosh format can be processed.

\section{Additional information}

More details about the submission of manuscripts should be obtained through the Editorial Office, preferably through e-mail (nig@nitg.tno.nl; nied@geo.vu.nl or dnieuw@xs4all.nl). 